These ideas are all taken up and expanded in Natural Capital. This is important, because the empirical evidence is that most countries do not account for the economic value of depreciating natural capital; nor have they put in place measures to hold the line. Helm's arguments bring the main problem raised by Malthus into a sharp new focus. Given current rates of world economic growth, incredible numbers of people, demands for resources and levels of pollution now loom, increasing pressures on ecosystems and biodiversity. Evidence is growing of the importance of ecosystem services such as clean water and pollination, and of the erosion of human well-being that results when those services are disturbed. That does not mean that economic growth should be stopped (even if that were possible), but it does demand a fundamental change in government policies globally.

As Helm drives home, these changes relate most fundamentally to a new goal of economic policy: keeping natural capital from declining. Many of the assets that make up natural capital deliver benefits that the market does not value, but which are important for well-being. So adopting such a policy would mean that as a country depletes its oil reserves, for example, it would reinvest a proportion of the returns from this activity in promoting renewable alternatives.

That demands a number of moves. A country must change the way it undertakes its national accounting to reflect the year-onyear changes in the value of all of its assets, including natural capital; it must tax pollution while removing perverse subsidies for activities that deplete natural capital; it must enforce strict limits on the use of renewable resources to maintain them above critical thresholds; it must require general offsetting of the negative effects of infrastructure projects. Moreover, it must increase the provision of public goods such as national parks and green spaces.

These are not new ideas (most were discussed in Blueprint for a Green Economy), but Natural Capital provides a very useful update and pulls together the past 20 years of economic insight in language that noneconomists will easily understand. For example, since 1989 economists have made great progress in estimating the values of ecosystem-service benefits. Helm has thought carefully about the practicalities of tracking changes in natural capital, of funding reinvestment in habitats, and of prioritizing actions through a focus on thresholds. As such, the book is a valuable contribution, written by an author who knows his subject and cares deeply about his message.

Nick Hanley is a professor of environmental economics at the University of St Andrews, UK. e-mail:ndh3@st-andrews.ac.uk

LIBRARY SCIENCE

\title{
The word on our archival future
}

\section{Michael Lesk assesses a work on the fate of the library at a time of economic and technological upheaval.}

$\mathrm{J}$ ohn Palfrey loves libraries and is optimistic about their future. In BiblioTech, he describes that future. In his vision, public libraries, as a mainstay of informed democratic societies, will share access to online material as well as to the physical books and spaces that resonate emotionally with users.

Palfrey - who helped to set up the Digital Public Library of America at Harvard University in Boston, Massachusetts - shows that most libraries are facing a "perfect storm": waning use, inadequate resources and users satisfied with easy personal access to online information. Although the book does not focus on academic libraries, US research libraries saw a $69 \%$ decline in the number of queries handled between 1991 and 2012. US research librarians answer some 7 million questions each year; Internet search engines handle that many every two minutes. Academic-library budgets are shrinking: spending has dropped from 3.7\% of the total budget of a typical US university in the early 1980 s to $1.8 \%$ in 2011.

Roughly half of an academiclibrary budget is spent on acquisitions, and that is increasingly consumed by journalsubscription prices. However, open-access publishers such as the Public Library of Science (PLOS) provide information with no reader fee, changing the economics entirely.

As Palfrey notes, school libraries - which still have a key role in teaching scholarly habits and propelling children towards a life in science - are suffering, often losing their staff. The 2010 Google Map 'A Nation Without School Librarians' is a grim indicator of the trend, showing the districts that have eliminated certified school-librarian positions. As for public libraries, the Pew Research Center reports that only about half of people in the United States used one in 2013. Palfrey is fearful that in the future, not everyone will have access to reliable information, and he is unconvinced that poorer people and nations will
DNATURE.COM For more on science in culture see: nature.com/ booksandarts

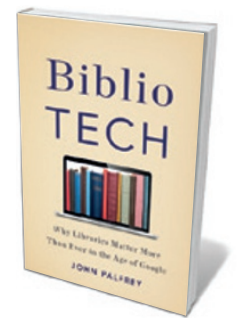

BiblioTech: Why Libraries Matter More Than Ever in the Age of Google JOHN PALFREY Basic: 2015. have equal access to information online.

The increasing commercialization of information raises further barriers. Palfrey is especially concerned about the copyright status of out-of-print books. Nobody makes money from them, but legal problems such as the dilemma of 'orphan books' (volumes in copyright, but for which the owner is unlocatable) prevent libraries from providing such volumes online. Finally, Palfrey, echoing the concerns of Google vice-president Vint Cerf among others, feels that digital preservation of library holdings is riskier than traditional methods. In my view, this is not entirely accurate: a single paper copy can fade or go up in smoke, whereas multiple digital copies can stay safe and affordable.

At a time of austerity and belt-tightening, will governments recognize the importance of libraries and librarians? The school library should be as important as the school sports team, I feel. Political will is essential, as is innovative energy among librarians. Palfrey hopes that conventional and new library technologies will sit side by side. This is not common in technological change: carrental companies do not run livery stables. I suspect that a more likely future is that libraries (and museums) will be divided into the 'wholesalers' that have large historic collections, such as the US Library of Congress or the British Library, and the 'retailers' such as university libraries, which serve faculties.

Anyone interested in the future of libraries - and whether there is one at all - will find much to mull over in this book. I hope its effectiveness will match its enthusiasm.

Michael Lesk is professor of information science at Rutgers University in New Brunswick, New Jersey, and chair of its department of library and information science.

e-mail:lesk@rci.rutgers.edu 